\title{
Impairment of active avoidance learning and sensory motor reflexes in mice offspring induced by perinatal acute toxic exposure to selenium
}

\author{
Gada Al Basher $^{1}$, Hossam Ebaid ${ }^{1,2}$, Jamaan Ajarem $^{1}$ and Gasem Abu-Taweel ${ }^{3}$ \\ ${ }^{1}$ Department of Zoology, College of Science, King Saud University, Saudi Arabia, P.O.Box 2455, Riyadh - 11451. \\ ${ }^{2}$ Department of Zoology, Faculty of Science, El-Minia University, Egypt. \\ ${ }^{3}$ Department of Biology, College of Education, Dammam University, P.O. 2375, Dammam - 31451, Saudi Arabia.
}

Accepted 7 June, 2011

\begin{abstract}
Selenium is an essential element with a narrow margin between beneficial and toxic effects. The learning and sensory motor reflexes-changes were studied after the perinatal exposure of mice to acute toxic doses of sodium selenite. Atomic absorption as well as the behavioral observations were employed. Adult pregnant mice was assigned into three groups: the first group was remained as a control group; the second and the third groups were orally administrated sodium selenite at doses of 1 $\mathrm{mg} / \mathrm{Kg}(1 \mathrm{ppm})$ and $4 \mathrm{mg} / \mathrm{kg}(4 \mathrm{ppm})$ of the diet, respectively started from the $7^{\text {th }}$ day of gestation to the $15^{\mathrm{th}}$ day of birth. Results revealed that body weight gain came significantly lower in pups born to treated mothers than those of the control pups. The appearance of body hair and opening of eyes of the pups from treated mothers were delayed in a dose-dependent manner. Selenite also inhibited the sensory motor reflexes in all elements in a dose dependent manner. The active avoidance test indicated that selenite exposure was associated with learning impairment. Acetylcholine recorded a significant decrease in treated pups. Significant high concentrations of selenium in the brain, liver and kidney was detected, indicating active transfer of selenium from mothers during pregnancy and lactation periods.
\end{abstract}

Key words: Perinatal, sodium selenite, atomic absorption, acetylcholine, active avoidance test, sensory motor reflexes, mice.

\section{INTRODUCTION}

Environmental toxicity of selenium in humans is associated with symptoms such as anaemia, leucopoenia and many other health problems (Sunde, 2000; Mataix and Lippies, 2002; Tinggi, 2003). Attention has been paid recently to residual selenium returned to the soil (Oldfield, 1997). Although, the need for selenium in nutrition is well recognized, the question concerning the high doses of selenium for supplemental use is still being debated. Despite, sodium selenite is widely used as a source of $\mathrm{Se}$ in animal feed, it is not a natural nutritional form of selenium and it can create ecological problems (Kumar et al., 2010). Receiving selenium as selenomethionine, the chief natural nutritional form present in grain crops is better

\footnotetext{
*Corresponding author. E-mail: happy20070801@live.cn.
}

than sodium selenite (Schrauzer and Surai, 2009). The general population should be warned against the employment of selenium supplements for prevention of diseases. The benefits of selenium supplementation are still uncertain, and their indiscriminate use could generate an increased risk of toxicity (Miguel and Carmen, 2008).

Mechanisms lying behind detrimental effects of selenium are poorly understood yet. They can involve DNA damage induction and consequently, DNA damage response and repair pathways may play a crucial role in cellular response to selenium (Manikova et al., 2009). Toxicity of selenium, however, depends on many factors like the selenium species, amount ingested, age, physiological status, and dietary interaction with other nutrients (Mataix and Liopis, 2002). Data reported the memory and the other cognitive and behavioral problems induced by selenite-high doses are poorly available. This paper 
describes an attempt to determine the high dose-selenite induced neurobehavioral changes in an experimental model.

\section{MATERIALS AND METHODS}

\section{Experimental animals}

Male and female Swiss-Webster strain mice (8 weeks old) were housed in opaque plastic cages. Animals were kept under reversed lighting conditions with white lights. The ambient temperature was regulated between 18 and $22^{\circ} \mathrm{C}$. Food and water were available $a d$ libitum, unless otherwise indicated. The males were removed from the cages after pregnancy (appearance of vaginal plug was considered as day one of pregnancy), and the females were subjected to experimental treatments. Pregnant females was assigned into three groups: 1) the first group was remained as a control group given phosphate buffered saline via oral route, 2) the second and the third groups were orally administrated sodium selenite in the diet at doses of $1 \mathrm{mg} / \mathrm{Kg}$ and $4 \mathrm{mg} / \mathrm{kg}$, respectively started from the $7^{\text {th }}$ day of pregnancy to the $15^{\text {th }}$ day of birth (PD15). The common dose of selenium in animal feed is $0.3 \mathrm{mg} / \mathrm{kg}$ of diet of sodium selenite (Leeson et al., 2008; Calamari et al., 2009). Offsprings were subjected to the developmental, neurobehavioral and biochemical studies from the day of birth (PD1) until the day 40 (PD40).

\section{Behavioral and developmental motor reflexes}

The pups of each experimental group were culled to only eight per dam on PD0 and were left with their mothers until PD21. During the weaning period, three pups of each litter were color marked from the others without any consideration to its sex, and were subjected to various behavioral tests (described below) under dim lighting. All observations were recorded on PD1 and repeated every other day until PD21. These observations were used to measure the early development of sensory motor coordination reflexes together with morphological development in the pups.

\section{Sensory motor coordination reflexes}

Body weight: Weight is a useful indicator of development. Thus, the pups were weighed every alternate day from PD1 until PD21. Eye opening and hair appearance: The day at which the body hair fuzz appeared, and the eyes opened were also recorded. These two parameters are also useful morphological indicators of development. Righting reflex: The time taken by a pup placed on its back to turn over and place all four paws on the substrate was recorded. An upper limit of $2 \mathrm{~min}$ is set for this test. Rotating reflex Pups were placed on the surface with their heads pointed downwards. The time elapsed until the pup rotate its body through $180^{\circ}$ geonegatively and face its head upwards was recorded as the rotating time. Cliff avoidance Pups were placed on the edge of a table top with the forepaws and face over the edge. The time taken by the pup to back away and turn from the "cliff" was recorded.

\section{Learning and memory test in automatic reflex conditioner} (shuttle box)

Animals of PD35 were tested using an automated shuttle-box (Ugo basile, Italy). The shuttle-box was divided into two chambers of equal size with a gate providing access to the adjacent compartment. A light of $60 \mathrm{~W}$ for $5 \mathrm{~s}$ was switched alternately in the two compartments and used as a conditioned stimulus (CS) which preceded an electric shock ( $1 \mathrm{~mA}$ for $5 \mathrm{~s}$ ) by $5 \mathrm{~s}$ called the unconditioned stimulus. If the animal avoided the unconditioned stimulus by running into the dark compartment within $5 \mathrm{~s}$ after the onset of the CS, the shuttle box recorded an avoidance response. Each mouse was given 30 trials daily with a fixed intertribal interval of $20 \mathrm{~s}$. Without shock, the number of crossings between the chambers was recorded (intertrial crossing). The automated shuttle box recorded this parameter during the whole experimental period of 30 trials (Hacioglu et al., 2003).

\section{Estimation of acetylcholinestrase}

Brain of the tested animals was removed and gently rinsed in physiological saline $(0.9 \% \mathrm{NaCl})$, and then blotted in Whatman filter paper. The organ fresh weights were recorded and frozen until use. A $10 \%(w / v)$ homogenate of each frozen tissue was prepared and the supernatant was applied for enzyme assay. The acetylcholinestrase activity in the homogenized brain tissue was estimated by using acetyl chloride as the substrate. The specific activity of acetylcholinestrase was expressed as micromoles acetylcholine chloride hydrolysed per gram wet tissue weight per hour at $37 \pm 1^{\circ} \mathrm{C}$.

\section{Total selenium measurement}

This method was performed according to the previously described technique by Lechner-Doll et al. (1990). Total selenium in brain, kidney and liver tissues was measured using atomic absorption spectrophotometry, using a PC-based ZL4100 Atomic absorption spectrophotometer (Perkin-Elmer) equipped with auto-sampler or automated Zeeman-effect background correction (Spectra AA-600, Varian Instruments, Walnut Creek, CA). Tissues were homogenized in $0.25 \%$ triton $\mathrm{X}-100$ (10 ml diluent $/ \mathrm{g}$ tissue weight). Standard curves ranging from 40 to $800 \mathrm{ng} / \mathrm{ml}$ were performed. Tissue homogenates were diluted $1: 5$ in a diluent consists of $0.2 \%$ nitric acid, $0.1 \%$ Triton $^{\mathrm{TM}} \mathrm{X}-100,1 \% \mathrm{Pd}(\mathrm{NO} 3) 2$ and $0.1 \% \mathrm{Mg}\left(\mathrm{NO}_{3}\right)_{2}$ and then $20 \mu \mathrm{l}$ was injected. Two concentrations (600 and $100 \mathrm{ng} / \mathrm{ml}$ ) from the standard curves prepared from tissue homogenate were processed in duplicate and used as quality control samples for tissue samples. Other quality control samples spiked with selenite or L-selenomethionine at two different concentrations (one at 500 $\mathrm{ng} / \mathrm{ml}$ and one at $150 \mathrm{ng} / \mathrm{ml}$ )) were run with the tested samples. The standard procedure called for repeated analysis of samples for which the corresponding quality control (QC) sample showed a coefficient of variation greater than established acceptable values (that is, $>15 \%$ for high-QCs; by $>20 \%$ for low-QCs).

\section{Statistical analyses}

The data of body weight, morphological developments and sensory motor reflexes were compared within the experimental groups by the analysis of variance (ANOVA) and were subsequently analyzed by Student's t-test (Yamane, 1973).

\section{RESULTS}

Tissue concentration of selenium and the
acetylcholine level

The concentration of selenium was analyzed by atomic absorption in order to confirm the placental transfer of selenium to the tested organs. Significant high concentration of selenium was detected in the brain, kidney and 


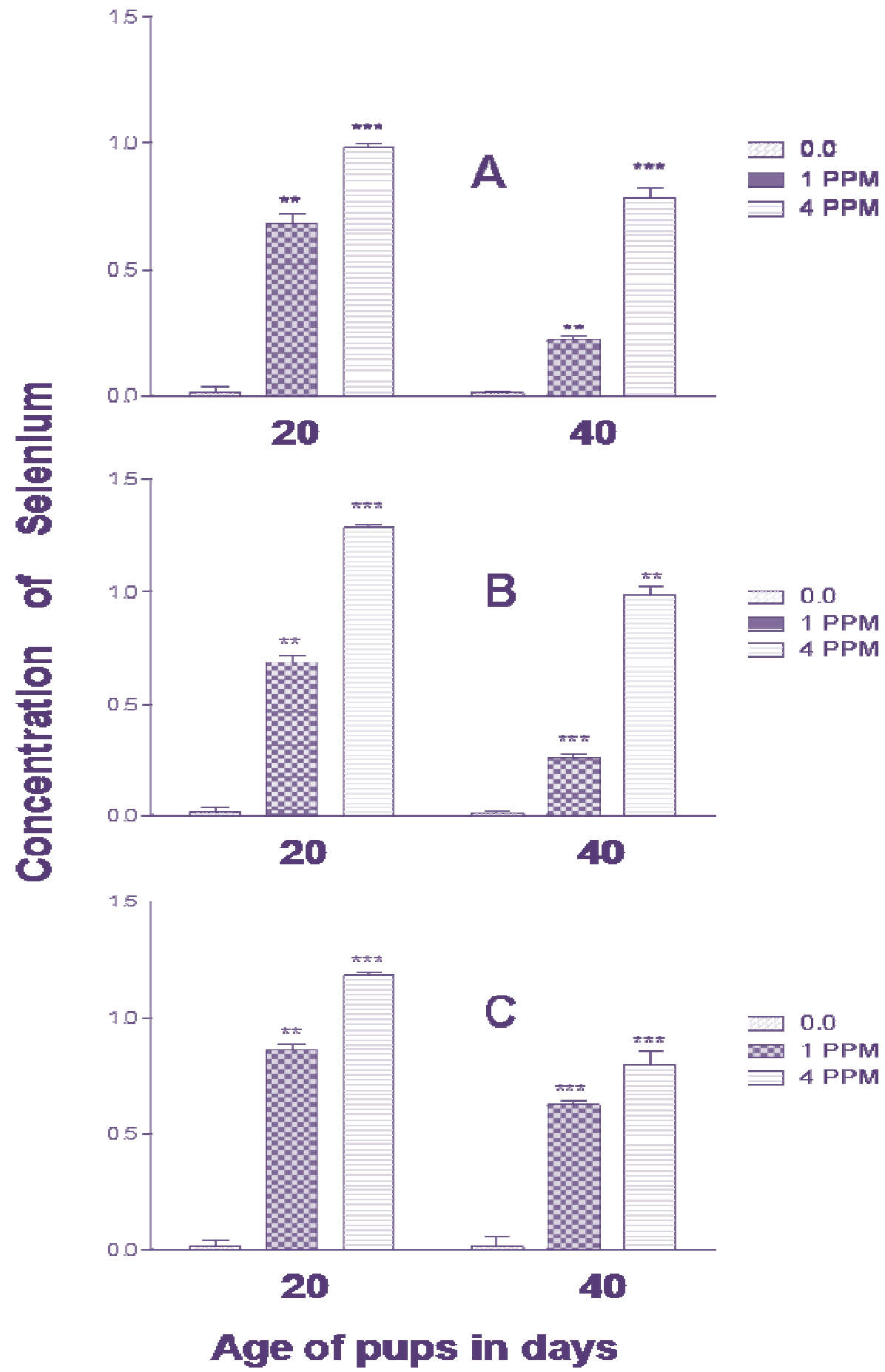

Figure 1. Total selenium measurement (mg/g tissue) in the brain (A), kidney $(B)$ and hepatic (C) tissues; Selenium was measured by electrothermal atomic absorption spectrophotometry. Selenium was detected in the developed pups-tissues at PD20 and PD40. Results are expressed as mean and standard errors $(\mathrm{M} \pm \mathrm{SE})$. The result was considered significant ${ }^{*}$ when $\mathrm{P}<0.05$ and highly significant ${ }^{* *}$ when $\mathrm{P}<0.01$.

liver tissues when tested on PD20 (Figure 1). On PD40, it was found also significant high concentrations of selenium in the same tested tissues. Acetylcholine is a clear biomarker to the behavioral changes. It recorded a significant decrease until PD 14 whenever, it started to elevate (Figure 2). 


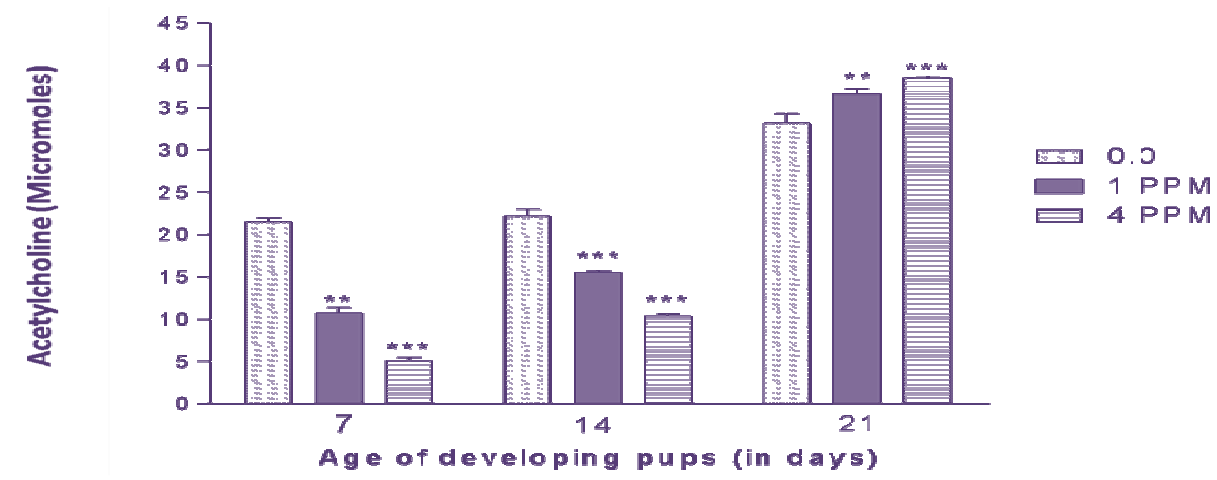

Figure 2. Acetyl cholinesterase estimation in the brain homogenates. Offspring were subjected to biochemical studies from the day of birth (PD1) until the day 21 (PD21). Results are expressed as mean and standard errors $(\mathrm{M} \pm \mathrm{SE})$. The result was considered significant ${ }^{*}$ when $\mathrm{P}$ $<0.05$ and highly significant ${ }^{* *}$ when $\mathrm{P}<0.01$.
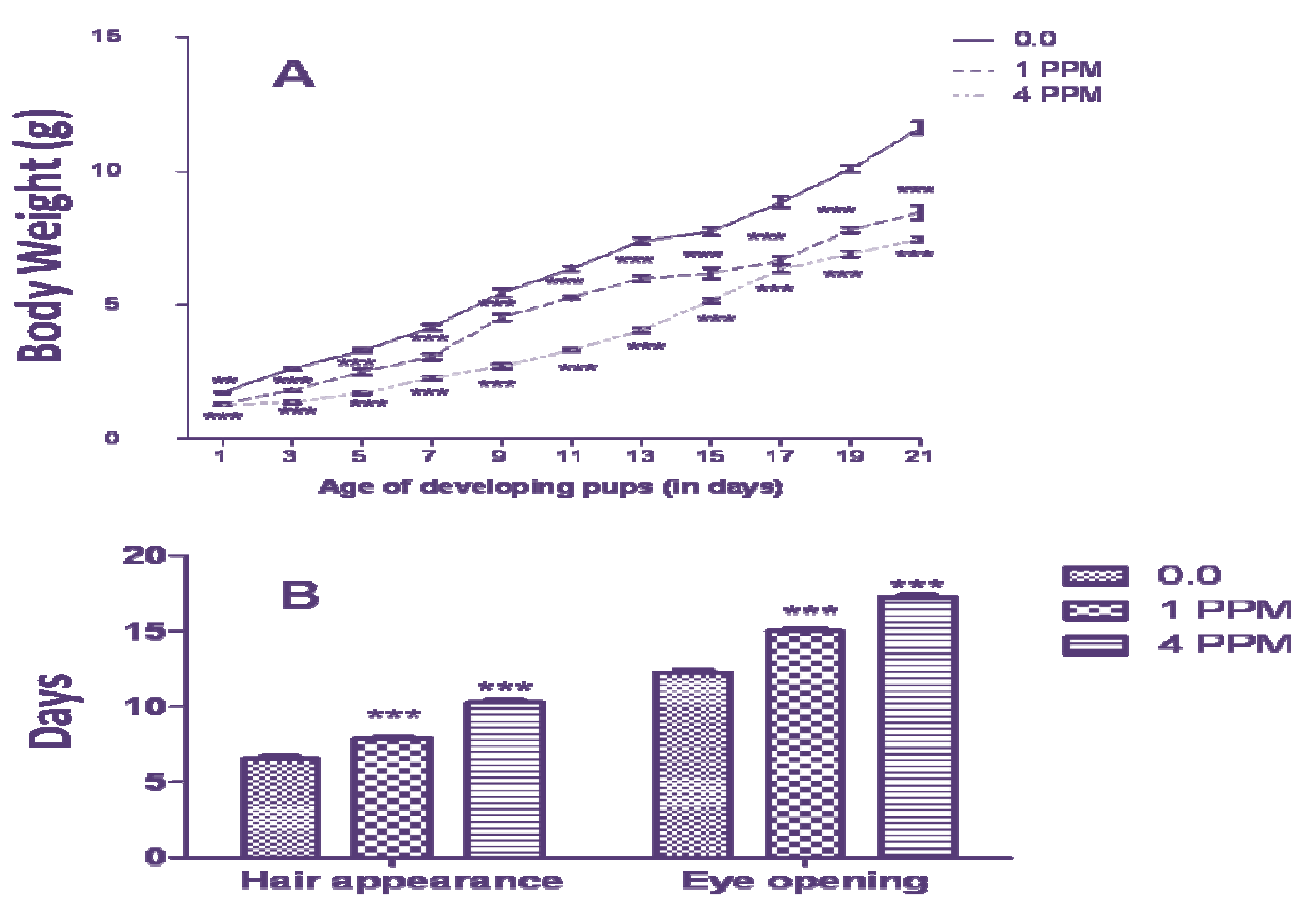

Figure 3. The morphological developments, namely, the body weight (upper), eye opening and body hair appearance (lower) of the developed control pups and those born to mothers consuming sodium selenite. All observations were recorded on PD1 and repeated every other day until PD21. Results are expressed as mean and standard errors $(\mathrm{M} \pm \mathrm{SE})$. The result was considered significant * when $\mathrm{P}<$ 0.05 and highly significant "* when $\mathrm{P}<0.01$.

\section{Selenium delayed the hair appearance and the eye opening}

Postnatal developments are crucial indicators for the selenite prenatal exposure-stress. From PD1 to PD21, the body weight gain, the hair appearance and the opening of eyes were daily observed. The body weight of pups born to mothers consuming sodium selenite lagged behind controls from the day of birth and remained so almost throughout their weaning period until PD21 in a dose-dependent manner. Eye opening and body hair appearance were significantly $(p<0.05)$ delayed after those of the controls (Figure 3 ).

\section{Early development of sensory motor reflexes were inhibited by selenium}

Neural tissues during embryogenic developments attract selenium. It was, therefore, expected that a direct change 

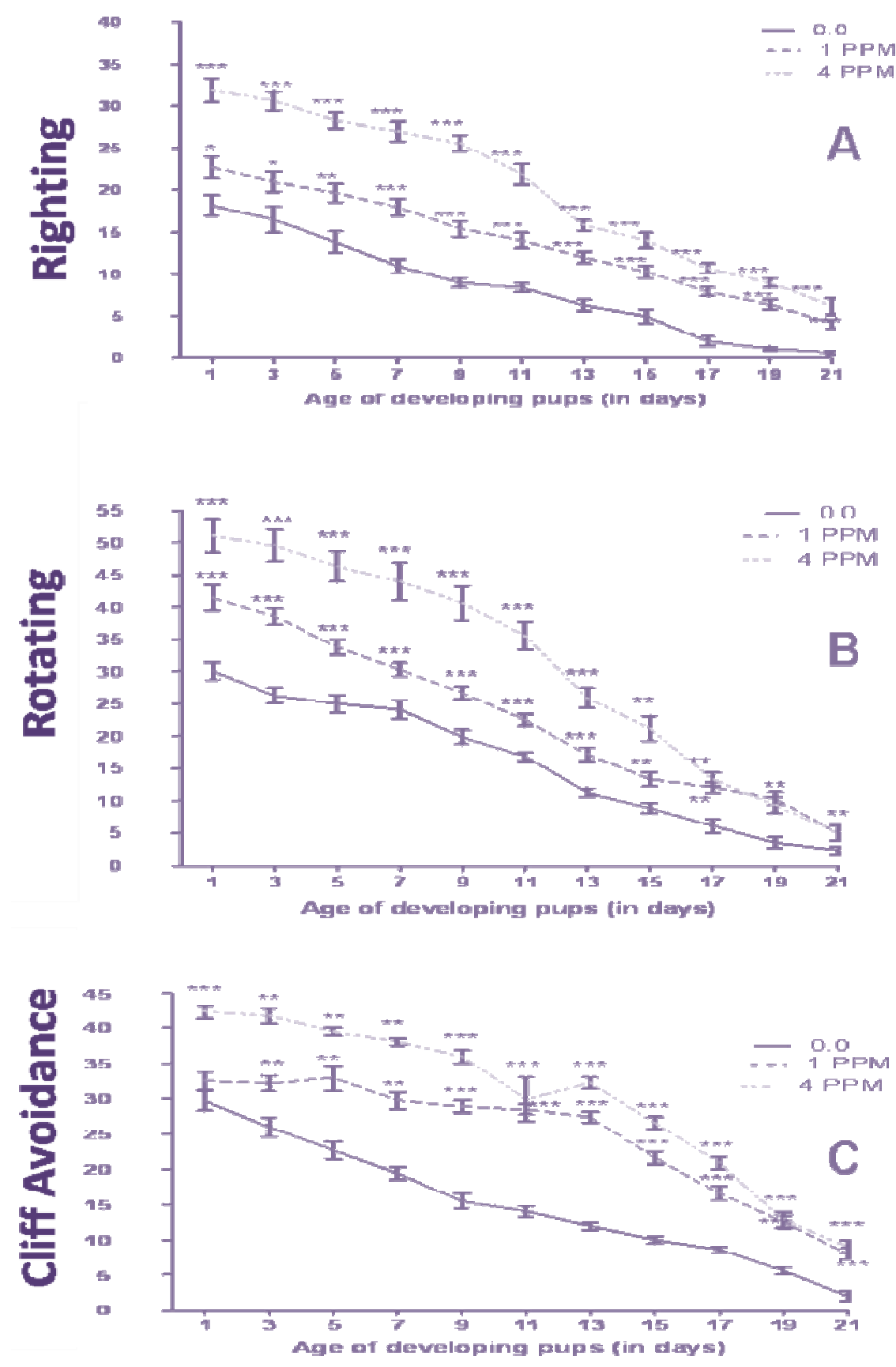

Figure 4. The early development of the different sensory motor reflexes in the pups born to both control and treated mothers. A: the mean righting reflex in seconds; $\mathrm{B}$ : The rotating reflex; C: The cliff avoidance reflex in seconds. Pups born to treated mothers were inactive comparing to the controls. All observations were recorded on PD1 and repeated every other day until PD21. Results are expressed as mean and standard errors $(M \pm S E)$. The result was considered significant * when $\mathrm{P}<0.05$ and highly significant ${ }^{* *}$ when $\mathrm{P}<0.01$.

in behavioral elements must be occurred. Both the sensory motor reflexes and the ability of the tested animals for learning were addressed. Perinatal exposure of mice to selenite had a significant and dose dependent inhibitory effect on the early development of all sensory motor reflexes in the pups. During the first three weeks of the postnatal development, selenite had a dosedependent and significant inhibitory effect on the righting reflex, the rotating reflex and the cliff avoidance activity especially at the higher dose (Figure 4). 

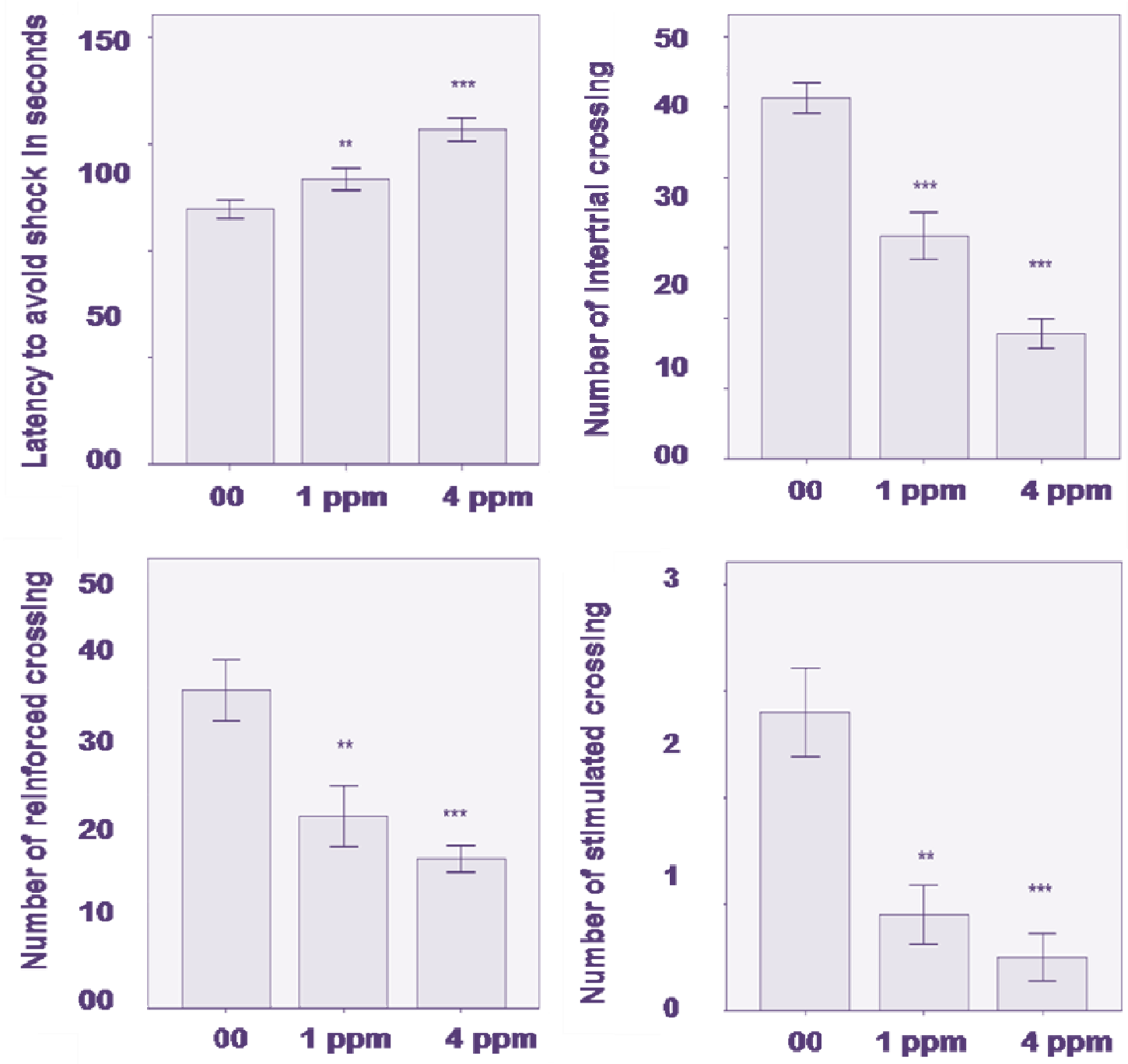

Figure 5. Learning and memory test in automatic reflex conditioner (shuttle box) showing the latency to avoid shock in seconds (upper right), the number of intertrial crossing between the two compartments (upper left), the number of reinforced crossing (lower right) and the number of stimulating crossings in seconds (lower left). All observations were recorded on PD35 and repeated for 3 days and each mouse was given 30 trials daily with a fixed intertribal interval of 20 seconds. The results were expressed as the mean percentage of avoidance responses for each daily shuttle box session. The result was considered significant " when $\mathrm{P}<0.05$ and highly significant ${ }^{* *}$ when $\mathrm{P}<0.01$.

\section{Impairment of active avoidance learning and memory in shuttle box}

Results of learning showed that high concentration of selenite has impaired the avoidance conditioning in the shuttle box. Impairment of active avoidance learning in all tested groups was clearly observed. It was observed that the control groups learned to avoid the unconditioned stimulus by running into the other compartment during the unconditioned stimulus on almost all days of the experiment and recorded high success rates of avoidance response (Figure 4). The pups born to selenite-treated mothers did not learn to avoid the unconditioned stimulus and the number of crossings during the conditioned stimulus decreased over time during the experiment. They showed a dose-dependent significant increase of the latency to avoid the shock. The number of the intertrial crossings between the two compartments, the number of stimulating crossings and the number of the reinforced crossing between the two compartments (Figure 5) were significantly decreased.

\section{DISCUSSION}

Since it belongs to nutrients that are essential for health, 
selenium is recently applied to many attempts in different therapeutic approaches on animal models (Bartel et al., 2010; Hu et al., 2010; Venkitaraman et al., 2010; Jung and Seo, 2010; Williams et al., 2010; Serdar et al., 2009). The developmental toxicity of selenium is a nutritional, environmental and medicinal concern, with sodium selenite being the most compound of choice. We studied the perinatal exposure of gestated mice females to the widely applied, sodium selenite, on the postnatal development of pups, with an inhibitory role of selenium on the different investigated parameters. Thus, the present results clearly suggest that exposure to high doses of selenium is extremely harmful to the developing pups indicating an active transfer of selenium from mother to embryos. This was proved in the present study by the atomic absorption analysis that revealed high levels of selenium in all investigated tissues (brain, liver and kidney) of the offspring. The placental transfer of selenium in embryonic and fetal tissues has been investigated in mice in early, mid, and late pregnancy by Danielsson et al. (1990). They found that the placental transfer of selenium was increased with time after dosing and with progression from embryonic through fetal stages.

Results strongly revealed a statistically significant decline in body weight at selenite high-concentration as was found by Ferm et al. (1990). They noted fetal body weights and lengths were reduced in a dose-dependent manner. Selenium caused anorexia (Satoh et al., 1981) in which food and water uptake of mothers decreased to the minimum. Exposure to selenite also causes a decline in the ability of pups to lactation (Satoh, 2007), blocks the intestinal absorption of different food derivatives (Kasik and Rice, 1995) and decreases the level of thyroxine which affects the body weight (Kaprara and Krassas, 2006). Beside the possible oxidation and inhibition of protein synthesis in the body of the developed pups, selenite might induce oxidative stress in the secretary cells of the mammary glands in mothers. Therefore, this quantitatively decreased the feeding rate of their offspring and its subsequent body weight.

Recent studies have reported the toxicity and related oxidative stress of selenium (El-Demerdash, 2001; Fujimoto et al., 2009; Isai et al., 2009). There is a large body of evidence implicating oxidative stress and reactive oxygen species (ROS) in the mechanism of selenium toxicity (Isai et al., 2009; Misra and Niyogi, 2009). In oxidative stress, the metabolism of oxygen leads to generation of ROS which are able to oxidize almost all classes of macromolecules, including proteins, lipids and nucleic acids (Zachara et al., 2006; Fujimoto et al., 2009; Manikova et al., 2010). It was proved that selenite ions have the potential to induce oxidative DNA damage in the liver cell culture through either an increase in ROS formation (Fujimoto et al., 2009) or probably by inducing the imbalance of intracellular glutathione redox (Misra and Niyogi, 2009). It is more likely that in this study, liver greatly affected, since atomic absorption analysis proved the presence of high concentration of this element within the hepatic tissues. This explains the effects resulted within the cells during the early developmental stages. Therefore, an important reason of the decline in body weight gain might be that selenite inhibited the protein synthesis and/or oxidize protein macromolecules which were much more needed in the developed body muscles, especially at the beginning of life. Usami et al. (2008) investigated selenium embryotoxicity and found quantitative changes in proteins, growth inhibition and morphological abnormalities of cultured embryos.

Selenium affects the metabolic processes via changing either the structure and function of mitochondria or the mechanism of action of endocrine hormones which controls metabolism (Kohrle et al., 2005). Additionally, the delay in hair appearance might be due to the delay in the collagen protein-synthesis by oxidation. The retardation in the opening of eyes as it was attributed to an abnormality in the neural developments (Georgieff, 2007), it could strongly explain what has happened in the learning and memory, and in the sensory motor reflexes as discussed below. Myelin sheath of the neurons of the optic nerve is directly affected by selenium (Satoh et al., 1981). The possible DNA damage by selenite during pregnancy could affect the sensory motor reflexes of the early developmental stages. This obviously reflected on the different inhibited reflex activities. Gupta et al. (2001) observed a suppression effect of selenium on the sensory motor activities and imbalance in rodents. The high uptake of selenium in the embryo was in the neuroepithelium (Danielsson et al., 1990; Ferm et al., 1990; Usami and Ohno, 1996). Thus, significant abnormalities are involved the nervous system during developmental stages after exposure to selenite. Atomic absorption analysis proved the presence of high concentration of selenium within the brain tissues of the developed pups.

The active avoidance training-test indicated that selenite exposure was associated with learning impairment. Similar results for aluminum were obtained by Sun et al. (1999), Miu et al. (2003) and Abu et al. (2010). Selenium impaired the learning and memory centers in the brain (Roig et al., 2006) especially when exposure taken place during gestation (Lam et al., 2002). It also leads to the degeneration of neurons in hippocampus which plays an important role in learning process (Guo et al., 2010). A growing body of evidence suggests that reactive ROS play a crucial role in the development of these impairments as discussed above (Kucukatay et al., 2007; Yamada et al., 1995). The increased production of oxidants altered neurotransmitter release and increased membrane permeability (Gupta et al., 1991). Besides, free radicals may degrade nitric oxide (NO), which plays an important role as a diffusible intercellular signaling molecule (a neurotransmitter in the central nervous system) (Geyer et al., 1997). Acetylcholine can be a marker in teratological studies (Ajarem and Ahmad, 1991; 1998), since any change in the behavior process due to any toxicant is indicated by alteration in acetylcholine (Reddy et al., 2003). It was found that selenite suppressed 
the acetylcholine at PD7 and at PD14. Thus, delayed sensory motor reflexes are also explained by the significant decrease of acetylcholine, the most important neurotransmitter. The direct result of this decrease is the disturbance of neuromuscular signals and therefore, the inhibitory effects in all elements of acts and postures in pups born to treated mothers. It has been reported that alteration in the brain enzymes are among the factors responsible for disturbances in behavioral activities of the affected animals (Ajarem and Ahmad, 1998). Taken together, these could explain why sensory motor reflexes were retarded.

This study, by atomic absorption analysis, confirmed the placental transfer of selenium to the tissue of embryos from treated mothers in a prenatal exposure. Selenium which was detected in the brain, liver and kidney of the pups, strongly affected the learning, sensory motor reflexes and acetylcholine levels. Thus, selenium at high doses is highly toxic to the tissue of embryos. Based on this study and other previous studies (Goldhaber, 2003; Miguel and Carmen, 2008; Ajarem et al., 2011), we expect that chronic supplementation of selenium can cause serious effects especially abnormal functioning of the nervous system. Therefore, when applied in the therapeutic approaches especially in gestation, selenium must be eventually monitored.

\section{ACKNOWLEDGEMENT:}

The Authors extend their appreciation to the Deanship of Scientific Research at king Saud University for funding the work through the research group project No. RGPVPP-028.

\section{REFERENCES}

Abu TG, Ajarem J, Ebaid H (2010). Aluminum-induced testosterone decrease resulted in physiological and behavioral changes in male albino mice. Afr. J. Biotechnol., 10(2): 201-208.

Ajarem JS, Ahmad M (1991). Behavioural and biochemical consequences of perinatal exposure of mice to instant coffee: a correlative evaluation. Pharmacol. Bioch. Behav., 40: 847-852.

Ajarem JS, Ahmad M (1998). Effects of perinatal exposure of Mice to nonalcoholic malt beverage "beer" on the offspring. Saudi J. Biol. Sci., 5: 78-92.

Ajarem JS, Al Basher G, Ebaid H (2011). Neurobehavioral changes in mice offspring induced by prenatal exposure to sodium selenite. Biologia, 66(2): 357-364.

Bartel J, Charkiewicz E, Bartz T, Bartel J, Schmidt D, Grbavac I, Kyriakopoulos A (2010). Metalloproteome of the prostate: carcinoma cell line DU-145 in comparison to healthy rat tissue. Cancer Genomics Proteomics, 7(2): 81-86.

Calamari L, Ferrari A, Bertin G (2009). Effect of selenium source and dose on selenium status of mature horses. J. Anim. Sci., 87(1): 167178.

Danielsson BR, Danielson M, Khayat A, Wide M (1990). Comparative embryotoxicity of selenite and selenate: uptake in murine embryonal and fetal tissues and effects on blastocysts and embryonic cells in vitro. Toxicol., 63(2): 123-136.

El-Demerdash FM (2001). Effects of selenium and mercury on the enzymatic activities and lipid peroxidation in brain, liver, and blood of rats. J. Environ. Sci. Health B., 36(4): 489-499.
Ferm VH, Hanlon DP, Willhite CC, Choy WN, Book SA (1990). Embryotoxicity and dose-response relationships of selenium in hamsters. Reprod. Toxicol., 4(3): 183-190.

Fujimoto Y, Morinaga K, Abe M, Kitamura T, Sakuma S (2009). Selenite induces oxidative DNA damage in primary rat hepatocyte cultures. Toxicol. Lett., 5(191): 341-346.

Georgieff MK (2007). Nutrition and the developing brain: nutrient priorities and measurement. Am. J. Clin. Nutr., 85(2): 614S-620S.

Geyer O, Podod SM, Mittag T (1997). Nitric oxide synthase activity in tissues of the bovine eye. Graefes Achieves Clin. Exp. Ophthalmol., 235: 786-793

Goldhaber SB (2003). Trace element risk assessment: essentiality vs. toxicity. Regul. Toxicol. Pharmacol., 38: 232-242.

Gupta A, Hasan M, Chander R (1991). Age-related elevation of lipid peroxidation products: diminution of superoxide dismutase activity in central nervous systems of rats. Gerontol., 37: 305-309.

Guo RZ, Zhou WQ, Luo ZG (2010). Effect of modified huanglian wendan decoction in treating senile patients with mild cognitive impairment of turbid-phlegm blocking orifice syndrome. Zhongguo Zhong Xi Yi Jie He Za Zhi 30(1): 33-36.

Hacioglu G, Agar A, Ozkaya G (2003). The effect of different hypertension models on active avoidance learning. Brain Cogn., 52: 216-222.

Hu Y, Mclntosh GH, Le Leu RK, Young GP (2010). Selenium-enriched milk proteins and selenium yeast affect selenoprotein activity and expression differently in mouse colon. Br. J. Nutr., 29: 1-7.

Isai M, Sakthivel M, Ramesh E, Thomas PA, Geraldine P (2009). Prevention of selenite-induced cataractogenesis by rutin in Wistar Rats. Mol. Vis., 15: 2570-2577.

Jung HJ, Seo YR (2010). Current issues of selenium in cancer chemoprevention. Biofactors, 36(2): 153-158.

Kaprara A, Krassas GE (2006). Selenium and thyroidal function; the role of immunoassays. Hell J. Nucl. Med., 9(3): 195-203.

Kohrle J, Jakob F, Contempre B, Dumont JE (2005). Selenium, the thyroid, and the endocrine system. End. Rev., 26(7): 944-984.

Kucukatay V, Agar A, Gumuslu S (2007). Effect of sulfur dioxide on active and passive avoidance in experimental diabetes mellitus: Relation to oxidant stress and antioxidant enzymes. Int. J. Neurosci., 8: 1091-1107.

Kumar BS, Tiwari SK, Manoj G, Kunwar A, Amrita N, Sivaram G, Abid Z, Ahmad A, Khan AA, Priyadarsini KI (2010). Anti-unlcer and antimicrobial activities of sodium selenite against Helicobacter pylori: in vitro and in vivo evaluation. Scand. J. Infect. Dis., 42(4): 266-274.

Lam KS, Gustavson DR, Pirnik DL, Pack E, Bulanhagui C, Mamber SW, Forenza S, Stodieck LS, Klaus DM (2002). The effect of space flight on the production of actinomycin D by Streptomyces plicatus. J. Microbiol. Biotechnol., 29(6): 299-302.

Lechner-Doll M, Rutagwenda T, Schwartz HJ, Schultka W, Engelhardt WV (1990). Seasonal changes of ingesta mean retention time and fore stomach volume in indigenous grazing camels, cattle, sheep and goats on a thornbush savannah pasture. J. Agric. Sci., (Cambridge) 115: 409-420.

Leeson S, Namkung H, Caston L, Durosoy S, Schlegel P (2008). Comparison of Selenium Levels and Sources and Dietary Fat Quality in Diets for Broiler Breeders and Layer Hens. Poult. Sci., 87: 26052612.

Manikova D, Vlasáková D, Loduhová J, Letavayová L, Vigasová D, Krascsenitsová E, Vlcková V, Brozmanová J, Chovanec M (2010). Investigations on the role of base excision repair and nonhomologous end-joining pathways in sodium selenite-induced toxicity and mutagenicity in Saccharomyces cerevisiae. Mutagenesis, 25(2): 155-162.

Mataix VJ, Llopis J (2002). Minerales. In: Mataix Vedu J, editor. Nutrición y Alimentación Humana, Madrid, 1: 211-245.

Miu AC, Andreescu CE, Vasiu R, Olteanu Al (2003). A behavioral and histological study of the effects of long-term exposure of adult rats to aluminum. Int. J. Neurosci., 113(9): 1197-1211.

Miguel NA, Carmen CV (2008). Selenium in food and the human body: A review. Sci. Total Environ., 400: 115-141.

Misra S, Niyogi S (2009). Selenite causes cytotoxicity in rainbow trout (Oncorhynchus mykiss) hepatocytes by inducing oxidative stress. toxicol. in vitro, 23(7): 1249-1258. 
Reddy GR, Basha MR, Devi CB, Suresh A, Baker JL, Shafeek A, Heinz J, Chetty CS (2003). Lead induced effects on acetylcholinestrase activity in cerebellum and hippocampus of developing rats. Dev. Neurosci., 21: 347-352.

Roig I, Garcia R, Robles P, Cortvrindt R, Egozcue J, Smitz J, Garcia M (2006). Human fetal ovarian culture permits meiotic progression and chromosome pairing process. Hum. Reprod., 21(6): 1359-1367.

Oldfield JE (1997). Observations on the efficacy of various forms of selenium for livestock: a review. Biomed. Environ. Sci., 10(2-3): 280291.

Usami M, Ohno Y (1996). Teratogenic effects of selenium compounds on cultured postimplantation rat embryos. Teratog. Carcinog. Mutagen 16(1): 27-36.

Usami M, Mitsunaga K, Nakazawa K, Doi O (2008). Proteomic analysis of selenium embryotoxicity in cultured post implantation rat embryos. Birth Defects Res. B Dev. Reprod. Toxicol., 83(2): 80-96.

Venkitaraman R, Thomas K, Grace P, Dearnaley DP, Horwich A, Huddart RA, Parker CC (2010). Serum micronutrient and antioxidant levels at baseline and the natural history of men with localised prostate cancer on active surveillance. Tumor Biol., 31(2): 97-102.

Satoh H (2007). My experience in mercury toxicology: behavioral teratology study of the effects of prenatal exposure to environmental pollutants. Nippon Eiseigaku Zasshi, 3: 881-887.

Satoh H, Suzuki T, Nobunaga T, Naganuma A, Imura N (1981). Effects of sodium selenite on distribution and placental transfer of mercuric mercury in mice of late gestational period. J. Pharmacobiodynamics, 4(3): 191-196.
Schrauzer GN, Surai PF (2009). Selenium in human and animal nutrition: resolved and unresolved issues. A partly historical treatise in commemoration of the fiftieth anniversary of the discovery of the biological essentiality of selenium. Curr. Res. Biotechnol., 29(1): 2-9.

Serdar MA, Bakir F, Haşimi A, Celik T, Akin O, Kenar L, Aykut O, Yildirimkaya $M$ (2009). Trace and toxic element patterns in nonsmoker patients with noninsulin-dependent diabetes mellitus, impaired glucose tolerance, and fasting glucose. Int. J. Diab. Dev. Count., 29(1): 35-40.

Sun X, Liu Z, Zhang X, Zhang Z (1999). Effects of aluminum on the number of neurons granulovacuolar degeneration in rats. Wei Sheng Yan Jiu., 30; 28(3): 164-166.

Sunde RA (2000). Selenium. In: Stipanuk MH, editors. Biochemical and physiological aspects of human nutrition. New York: W.B. Saunders Company, pp. 782-809.

Tinggi $U$ (2003). Essentiality and toxicity of selenium and its status in Australia: A review. Toxicol. Lett., 137: 103-10.

Williams CD, Satia JA, Adair LS, Stevens J, Galanko J, Keku TO, Sandler RS (2010). Antioxidant and DNA methylation-related nutrients and risk of distal colorectal cancer. Cancer Causes Control., 21(8): 1171-1181.

Yamada K, Noda Y, Nakayama S (1995). Role of nitric oxide in learning, and memory and in monoamine metabolism in the rat brain. Br. J. Pharmacol., 115: 852-58.

Yamane T (1973). Statistics an introductory analysis. $3^{\text {rd }}$ ed. London, Harper and Row Publishers, pp. 647-650. 